Portland State University

PDXScholar

Engineering and Technology Management

Faculty Publications and Presentations

8-1-2015

\title{
Project Management in Product Development: Toward a Framework for Targeted Flexibility
}

Antonie J. Jetter

Portland State University, ajetter@pdx.edu

Fatima Albar

Portland State University

Follow this and additional works at: https://pdxscholar.library.pdx.edu/etm_fac

Part of the Operations Research, Systems Engineering and Industrial Engineering Commons Let us know how access to this document benefits you.

\section{Citation Details}

Jetter, A., \& Albar, F. (2015). Project management in product development: Toward a framework for targeted flexibility. In 2015 Portland International Conference on Management of Engineering and Technology (PICMET) (pp. 1562-1575). IEEE. http://doi.org/10.1109/PICMET.2015.7273107

This Article is brought to you for free and open access. It has been accepted for inclusion in Engineering and Technology Management Faculty Publications and Presentations by an authorized administrator of PDXScholar. Please contact us if we can make this document more accessible: pdxscholar@pdx.edu. 


\title{
Project Management in Product Development: Toward a Framework for Targeted Flexibility
}

\author{
Antonie Jetter, Fatima Albar \\ Portland State University, Dept. of Engineering and Technology Management, Portland, OR - USA
}

\begin{abstract}
As a discipline, project management has been accused of having lost its relevance for innovative initiatives because it emphasizes planning and control over the flexibility and learning-based strategies that are needed to succeed under uncertainty. Several authors therefore recommend adaptive project management practices - sometimes named "targeted flexibility" - that respond to project characteristics commonly found in innovation, namely novelty, complexity, speed and - as a result - uncertainty. This paper investigates how this proposed adaptation of project management occurs in a context with high levels of novelty that organizes work in projects and needs to accommodate projects of different pace, complexity and innovativeness: product development in small and medium enterprises that do research and development work in the same organizational unit. Results of a literature review and two exploratory studies, covering a total of 8 companies with multiple projects each, are presented. Implications for a future framework for targeted flexibility are developed, leading to the identification of the following needs for project management: (1) better understanding of the many ways in which project management impacts exploration and exploitation activities, (2) improved attention for the currently poorly supported preproject and early initiation stages, (3) a shift of focus from monitoring against plans toward monitoring against achieved learning, and (4) the formulation of transition paths from current new product development practice to higher project management maturity.
\end{abstract}

\section{INTRODUCTION}

"what is sound management practice for incremental innovation - where speed, cycle time, and quick cash recovery are primary objectives - might actually hamper the radical innovation's progress" [1].

The project management discipline has been accused of losing its relevance for innovation initiatives because it overemphasizes linear project management approaches that are well-suited for controllable projects but poorly adapted to high-uncertainty endeavors [2]. Lenfle and Loch [2] have therefore called for a new project paradigm, called targeted flexibility, that takes uncertainty into account and manages routine project modules with a planning-driven approach, whereas high uncertainty modules are managed through learning-based approaches. Adaptive approaches to project management have furthermore been recommended by [3] and [4]. Also, in order to tackle the challenge of complex projects, Project Management Institute (www.pmi.org), a leading knowledge provider to project management practitioners, increasingly emphasizes the importance of culture, talent management, and stakeholder communications. However, to date, PMI does not provide a standard for targeted flexibility and tools and practices for achieving it are scarce in the academic and the practitioner literature.

To help foster research on project management practices for highly innovative endeavors, this paper focuses on the context of new product development as a prototypical example of a project environment with high levels of innovation. Specifically, it investigates contributors for a future practice of targeted flexibility from three streams of literature: product innovation, organizational theory, and project management. Following the review and synthesis of the state-of-the-art it explores how the recommendations gleaned from the literature are implemented in practice. To this end, it investigates the project management practices of 8 different companies by analyzing multiple projects per company. Data analysis is not yet completed, but early results of this study already suggest the need for future research towards a framework for targeted flexibility.

The paper makes several contributions: First, it systematically reviews largely distinct streams of literature on product innovation, organizational ambidexterity, and project management, and integrates them into a research framework. Second, it opens the black box of project management practice in new product development and identifies companyspecific and project-specific adaptations of standard new product development and project management practices. Some of these adaptions are explicit, while others occur "under the radar. And third, it synthesizes these findings and provides recommendations for future directions of project management research, targeted at improving the disciplines relevance in product innovation.

\section{CONTRIBUTORS TO TARGETED FLEXIBILITY}

\section{A. Product Innovation Management}

Product development organizes work in projects and operates in a context with very high levels of innovation. Yet, the product innovation literature traditionally gives little attention to project management, as it has long been dominated by empirical research that investigates the link between product and project characteristics and product success [2],[3]. The research is not theory-driven and does not typically investigate the inside of the project management 'black box' [7] but provides managerial recommendations based on project factors that correlate with success. It recommends rigorous up-front planning, documentation of plans and progress to improve communication and commitment, cross-functional teams, and decision gates that secure senior management buy-in. Brown and Eisenhardt [7] characterize this approach as the rational plan perspective 


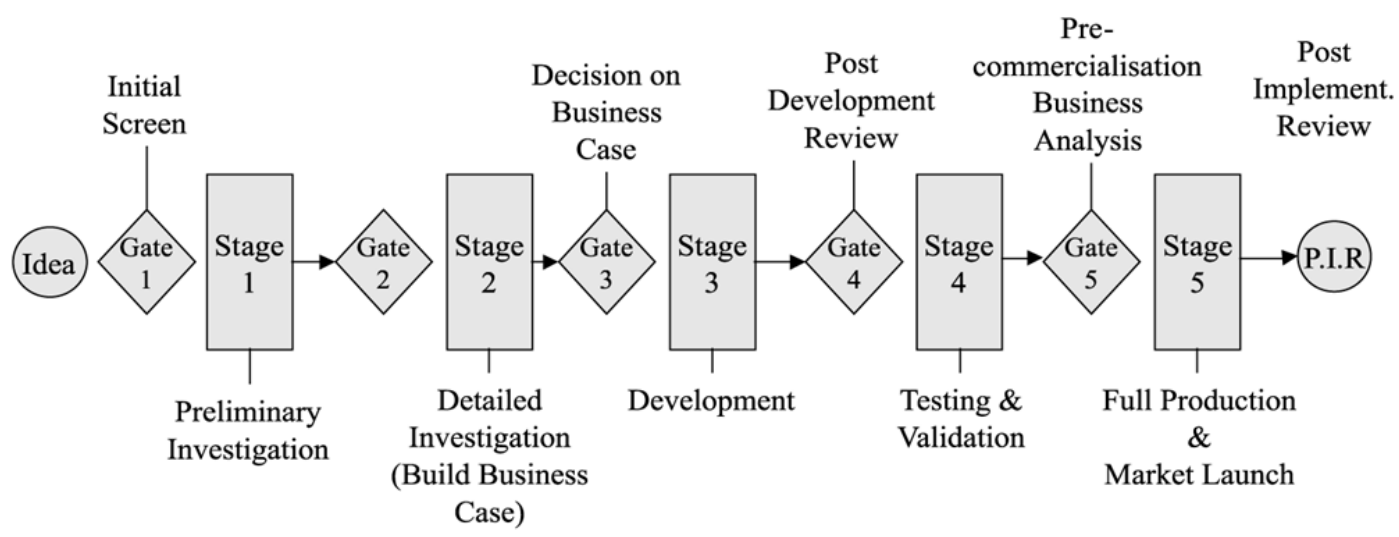

Source: Cooper (1994)

Figure 1. Stage-Gate for New Product Development

because it explains the success of new products as the result of carefully planning a superior product for a well-chosen business opportunity and executing this plan flawlessly.

This perspective has been highly influential in managerial practice. Accordingly, the most common approach to organizing new product development projects is a linear process model with decision points that separate sequential project phases, such as the Stage-Gate $\mathrm{C}$-system [8] or the generic product development model by Ulrich and Eppinger [9]. Gate reviews are based on objective criteria that reflect what the organization knows to be important for project success (see Fig. 1).

Each gate review requires a specific set of deliverables that spell out what actions should be taken and what information needs to be presented for the review [8], [10]. The self-documenting nature of the process enables continuous process improvement [11]. Linear process management approaches with gates have been linked to improved product success, but also criticized for being too specification-driven, rather than customer-driven, too heavyweight for simple projects, and too constraining for radical innovation [8], [12], [13].

One set of concerns focuses on the potential of introducing too much rigidity into organizational routines and cultures. To obtain approval, product development teams may commit to precise project parameters and freeze product specifications early in the development process, even against their better judgment [11], [14], [15]. After approval, a project team may engage in a project execution mindset and focus on the project plan and whatever is required to sail through the new gate, rather than making changes to the project to response to new market and technology insights [13]. The problem is aggravated by one of the principles of the Stage-Gate $\bigcirc$ methodology - 'do it right the first time' [16] that causes the process to not explicitly account for backtracking into earlier stages. Moreover, the fact that a project has passed formal reviews - often with high level management involvement - may make it difficult to later propose an alternative course of action or to terminate it [17]. Proponents of linear product development frameworks, such as Cooper [18], state that these concerns are sufficiently addressed within those frameworks. They point out that gate reviews should not be done in a bureaucratic manner, but review criteria should fit the specifics of the project. Moreover, conditional gates -paired with risk analysis- allow some projects to move forward, even if it has not yet met all gate criteria- however, according to Sethi and Iqual [13] with only limited impact on reducing unwanted rigidities.

A second set of concerns is focused at the practicability of the process under different conditions, such as innovations that require a very high level of user involvement [19], projects that follow open innovation paradigm [20], projects that are not focused on product, but on process innovation [21] or incremental projects for which a full gate review may be overkilling. These issues have typically addressed by both, theoretical expansions of the basic linear process model [8], and modifications of standard linear practices as they occur in industry practice [6], [22]. Among others, these changes allow companies to 'fast track' decisions by dropping stages, to revisit earlier stages, and to add iterative design-test-build cycles to acquire more meaningful customer input when knowledge is sticky [8]. This has led to a considerable expansion of options. When the Stage-Gate system was first conceptualized, it was intended to bring process management thinking to the innovation process by providing a "skeleton from which to develop a custom-tailored model" [23]. In current publication, recommendations are more complex and differentiate - among others - between major new products, moderately risk projects, and minor change projects, all of which are executed with a different version of the Stage-Gate model. Cooper's third generation Stage-Gate-Model, for example, is still inherently linear but provides flexibility to omit or bypass stages and gates and execute activities in parallel, as long as this occurs deliberately, consciously and 
with full awareness of facts, consequences, and risk [24]. For lower risk projects, Cooper subsequently developed 'lite' and 'Xpress' process versions and a significant customer request (SCR) variant with an iterative style customer involvement [8].

By moving away from a once relatively simple, linear standard process to a range of process options, the product innovation literature clearly demonstrates the need for targeted flexibility in managing innovative projects. Moreover, it increasingly discusses fundamental challenges to the success of structured management approaches in the so-called fuzzy front-end of radical innovation. The fuzzy front-end precede formal project evaluation and a go /no-go funding decision [25] and entails all activities up to and including gate 3 in Cooper's model (see Fig. 1). While Fig.1 implies a similarity between front-end and later stage decision-making, the literature states that front-end management may be substantially different from the management of later stages of new product development. According to Koen et al. [26] front-end is experimental, often chaotic, and difficult to plan and characterized by unpredictable commercialization dates, uncertain revenue expectations and variable budgeting approaches that often include bootstrapping. In contrast, the actual new product development project begins after the front-end and is structured, disciplined, and goal-oriented with a project plan. Accordingly, front-end research aims to manage front-end fuzziness [27]. This is achieved by keeping the front-end short and focused on developing stable project definitions, as well as by creating a system of evaluation points that is capable of quickly identifying and funding projects that will be technically and commercially successful, fit company strategy, and support the desired project portfolio mix [5], [28], [29]. According to Khurana and Rosenthal [30], two contrasting approaches are used to achieve these objectives: Some companies employ a formal front-end approach that prescribes a process with clear standards for building, documenting, and approving a business case for a new product development project. Others rely on a culture-driven, more emergent approach to develop a joint project vision and buy-in for development projects that relies on strong crossfunctional interactions and subtle control through management and stakeholder agreement. This informal process is suitable and more commonly applied for the frontend of radical new product innovations [30]-[32] .

One important observation of researchers is that some of the front-end fuzziness associated with radically new products appears to carry over into later product development stages. Veryzer [33] finds that product development teams in radical innovation projects still engage in considerable prototyping, lead user testing, and design modifications after project approval: In the case of discontinuous products many of the activities that one would expect should be undertaken prior to product development - understanding customer needs and market assessment - will necessarily lag slightly behind the design and (formative) prototyping steps that would normally precede. Verworn et al. [34] find that in radical new products, there are lower levels of clarity on competitors, market size, and customer price sensitivity, even after the project is approved [34]. Also, Lewis et al. [35] investigate project management styles and project uncertainty within a single company from six months after project start to project completion. Despite all having cleared front-end evaluation within the same organization, the projects differ greatly with regard to uncertainty levels in later stages of product development.

\section{B. Organizational Ambidexterity}

Organizational theory has long been interested in socalled ambidexterity, which enables companies to hone and exploit an existing knowledge base, as well as to explore innovative opportunities that build on different competencies. Exploitation initiatives are looking for solutions inside the existing technologies and for the existing market and therefore are more likely to have predictable return on investment. They increase the fit and alignment of the organization with the evolutionary changes in the market, e.g., by lowering costs or modifying product offerings to accommodate new customer requirements. In contrast, exploration initiatives are seeking solutions beyond the company's existing technologies or markets. They are vaguer, less certain and slower to produce results but give new competencies to the organization that allows it confront the revolutionary changes in the business environment, such as market shifts and the emergence of disruptive technologies [36]-[41]. Ambidexterity is a prerequisite for competitive success when business environments are neither slow to ever change or so volatile, that knowledge quickly become obsolete. In the first case, heavy emphasis on exploitation, paired with an incremental growth of the knowledge base suffices. In the latter case, the necessity to 'unlearn' old knowledge and frequently create new knowledge results in a strong emphasis on exploration.

The literature generally agrees that exploitation and exploration require different structures, processes, management styles, cultures, values, and even measures of success [36], [42], [43] [44] and that organizations typically emphasize one aspect over the other. Projects that do not fit the preferred model either are not approved at all, morphed into a different, more familiar project type, or defunded during execution. Table 1, adapted from Govindarajan \& Trimble [36], highlights the key differences between typical planning approaches for exploitation-oriented projects and planning principles for exploration: 
2015 Proceedings of PICMET '15: Management of the Technology Age

TABLE 1 PLANNING APPROACHES FOR EXPLORATION VS. EXPLOITATION PROJECT

\begin{tabular}{|l|l|}
\hline Planning principles for radical innovation & Project management practices for high performance \\
\hline Invest heavily in planning & Planning and management attention in proportion to budget \\
Create a plan and metrics for success from scratch & Use the last project as a template and modify \\
Discuss data and assumptions & Focus on data \\
Document a clear hypothesis of record & Document clear expectations \\
Find a way to spend a little, learn a lot & Be on budget, on time, and on spec \\
Create a separate forum for discussing radical innovation projects & All innovation projects are discussed in the same forum \\
Frequently reassess the plan & Deliver the results in the plan \\
Analyze trends & Analyze totals \\
Allow formal revisions to predictions & Revisions are frowned upon \\
Evaluate innovation leaders subjectively & Evaluate based on results \\
\hline
\end{tabular}

Because of these differences organizational theory frequently proposes to separate exploitation and exploration in space or time. In the case of structural differentiation these activities occur through two or more separate organizational units, such as a central research organization, a spin-off company, or an external design firm for exploration and product-focused development for exploitation [37], [40], [45]. This separation enables the organization to plan, lead, and evaluate exploration and exploitation teams with different styles and methods while using appropriate individuals and managers for each. A separation in time occurs when the organization practices exploitation or exploration for some period of time and then switches its emphasis and activities to the other practice [37], [39], [46], [47]. This process of transitioning is sometimes characterized as punctuated equilibrium.

The organizational separation of exploitation and exploration is theoretically intriguing but comes with considerable practical challenges. Separation by time forces companies to undergo times of major disruption, if not crisis, to make the transition from one stage to the next. Separation by organizational unit may result in exploration that ventures too far from what the market accepts. Companies may therefore not want to separate cutting-edge technology development from the strong product and market focus that their business units can provide. The demise of central research labs, such as Xerox Parc and Bell Labs speaks to this problem. Particularly smaller organizations may also find separation to be impractical if they do not have enough engineers and scientists to staff and consistently employ a separate research organization. They may also have little duplication of skills among their employees and therefore cannot assign individuals either to exploitation or exploration projects because their skillsets are needed in both. With blurry boundaries like this, however, all projects are likely to inherit the dominant organizational paradigm and separation is impossible. The problem is aggravated when products have high exploration content in product development, such as the design and manufacture of customer-specific specialty machinery. Finally, exploration is not only necessary in technology or product development, but may take the form of planning and testing a new service offering, logistics approach, or business model. Exploration projects of this nature are likely to include so many business functions that separation is impossible, short of recreating an entirely separate organization.

In response to the challenges of separation-based approaches to ambidexterity, organizational theory increasingly emphasizes the concept of integration. Integration refers to the degree to which the individuals who are responsible for exploration and exploitation organically relate to each other and transfer knowledge, information and experience [37], [40], [45], [46]. In its extreme form, integration occurs by charging individuals with both, explorative and exploitative activities, at the same time. While people are unlikely to equally excel at both activities [42], it appears that most individuals can perform ambidextrously to some extent. However, having ambidextrous individuals does not make an organization ambidextrous [37]. A supportive organizational context with strong social support and performance management [46] is needed, as are dense social relations [48]. Some of the integration appears to be achieved through project management: de-centralized decision making, such as empowered project teams, appear to improve explorative innovation without negative impacts on exploitation and a formalization of decision making through standard processes and manuals improves exploitation without harming exploration [48]. Moreover, project teams in complex projects appear to achieve temporal separation on the project level, rather than on the level of organizational units, as they "cycle" through phases of exploration and planning when they start working on new work break down structure items and execution and exploitation when they execute on these plans [49].

\section{Project Management}

The most common approach to organizing new product development projects is a linear process model with decision points that separate sequential phases in a project's lifecycle, such as the Stage-Gate-Model illustrated in Figure 1. The process is adapted from its first generation predecessor approach, developed by NASA's PPP (phased project planning) in early 1960 s, by adding - among others - a strong customer focus and cross-functionality. It thus shares the same roots as the project framework promoted by PMI (Project Management Institute) and globally used by project management professionals. The two frameworks, however, are not identical. Figure 2 maps SG phases (top row) against 


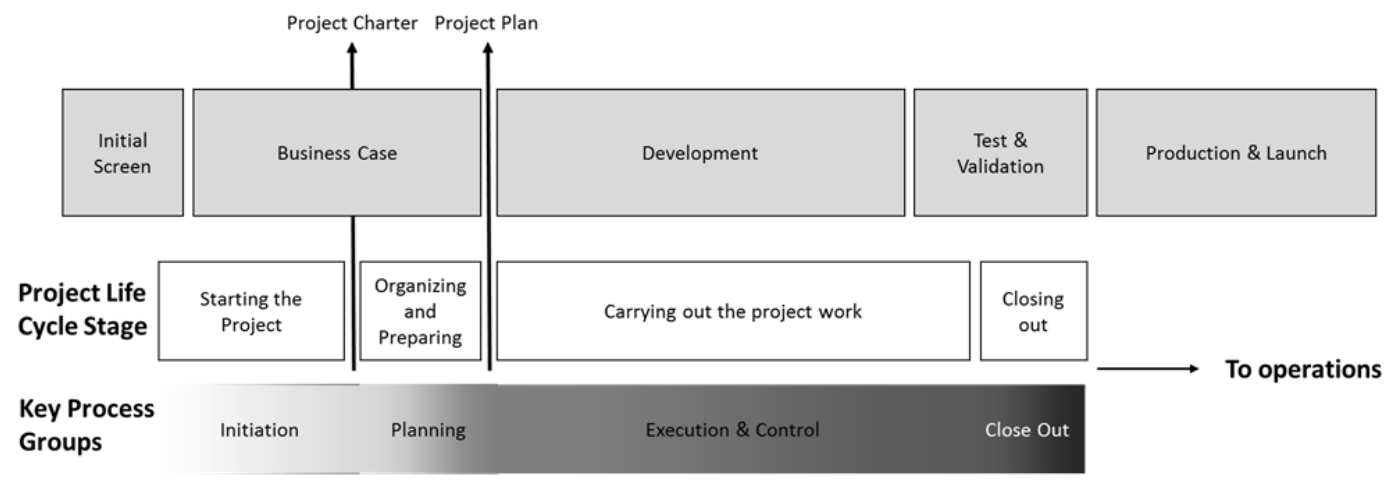

Figure 2: Stage-Gate and Project Management phases

project life cycle stages as described in PMI's standards [50]. Each project phase is characterized by its emphasis on particular project management processes (so-called process groups). The life cycle stage "start", for example, encompasses a variety of initiation activities, some of which may still carry over into later stages, even after the output of the phase, the project charter, is produced. Within the project management framework, a development project is typically considered complete when the product is handed off to manufacturing.

Table 2 compares key activities and instruments of SG, as described in the new product development literature to the key processes (as defined by PMI's standards). Notably, both frameworks have some similar phases, approaches, and outputs.

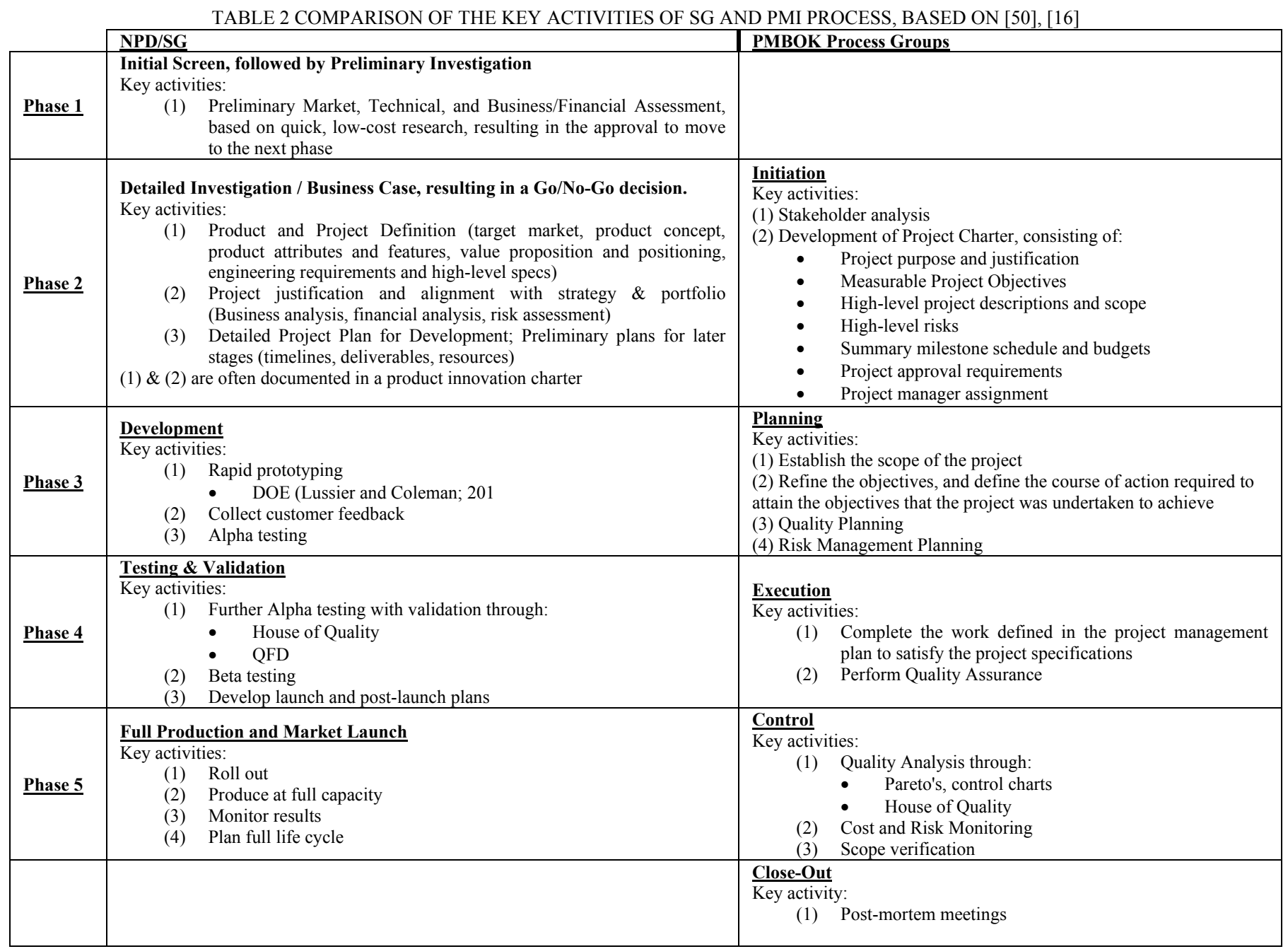


The SG framework puts heavy emphasis on the prioritization and selection of new product programs for longer term organizational goals [51], which occurs in a preproject stage or the front-end. This stage, which does not exist in the PMI framework, is considered to be central to product development success and one of the key contributions of SG models to NPD practice [52].

The PMI framework, on the other hand, follows the control theoretical philosophy of monitoring and steering project execution against plans and organizes planning, execution, and control in separate and distinct process groups. It measures project success by comparing product and project quality, timeliness, budget compliance, and degree of customer satisfaction against set targets (PMBOK). It also describes the role of the project managers as monitoring and controlling the work of producing the products, services, or results that the project was undertaken to produce. This view is somewhat at odds with that of NPD scholars who emphasize that "Stage Gate is not, and never was, intended to be a control mechanism" [16, p. 113] that allows management to manage projects on a micro level, such as timelines, staffing levels, budgets, or costs. The NPD literature therefore conceptualizes SG as a "business" or "macro" process that is broader in scope than project management but should be combined with project management on the micro level during development, testing, and launch[24], [52]. Similar assessments can also be found in the project management literature. For example, a 2008 study concludes that project management, while applicable to new product development, provides "incomplete perspectives on NPD" and therefore needs to be applied in combination with NPD approaches [53]. A recent empirical study [51] confirms this assessment: project management practices, if used on their own, fail to deliver positive results when innovativeness is high. SG has a positive effect on both, incremental and radical product development efforts. This effect is reinforced when PM practices are applied within a SG framework in a complementary fashion.

\section{Project management approaches for high uncertainty projects}

The product innovation and the project management literature have long attempted to characterize project contexts with regard to how much uncertainty they introduce to the project. Uncertainty can exist with regard to marketing and technology aspects of the product (e.g. what customer needs to address and what technical solutions to implement), as well as with regard to the how markets, technologies, and the general business environment will evolve in the future. Moreover, appropriate resource allocations to projects and within projects are also uncertain [54].

Most studies focus on what is uncertain (markets, technologies, environments, etc.) and do not further conceptualize why uncertainty occurs. Some authors understand uncertainty as an objective lack of information that can be healed by gathering additional information until only "residual" [55] uncertainty remains. This unavoidable uncertainty, for which no information is available, is relatively straightforward to manage through traditional risk management: areas of uncertainty are documented, assessed with regard to their likelihood of occurrence and the severity of consequences, and addressed with various risk mitigation strategies. The underlying notion of these approaches is that decision-makers fundamentally understand how project elements and the project environment are linked. They may, for example, know that a weaker dollar affects project cots, but they do not know the dollar exchange rate at the time that payments come due. Other authors [56], [57], however, point out that uncertainty is perceptual. It exists when a decisionmaker is unable to fully understand the relationships between project elements. Miliken differentiates state uncertainty (inability to predict the future state of a variable), effect uncertainty (inability to judge the impact of a changing variable) and response uncertainty (lack of information about response actions and their effects). These uncertainties preclude the decision-maker from using traditional risk management approaches. They persist because the situation is so novel (e.g. markets with entirely new usage patterns, emerging technologies) and so complex that it is impossible for the decision-maker to articulate relevant variables and their functional relationships [58], [59]. This situation is characterized as ambiguity [56], unforeseeable uncertainty [59], Unk Unks or Unknown Unknowns [60] or "deep uncertainty" [61]. It is a result of lack of information, as well as the persistence of so-called "rugged" project landscapes in which adjacent points of project performance are loosely related [59] and project interdependencies cause a small changes in one project element to result in large changes in overall project performance. A common analogy for this phenomenon is search in a geographical region: In projects with lack of information, but without unk unks, project managers know where the point of best project performance is because the one peak in the region is clearly visible from everywhere, similarly to the view of Mount Hood from the plains of the Willamette Valley. Project management plans aim for the peak and plan for risks that can occur along the way. In uncertain projects managers are operating in deep fog and cannot see the performance peak or peaks. However, they can see a little bit of road in front of them and can see if it slopes upward or downwards. In a non-rugged landscape, consistently moving forward on a road with an upward slope will eventually cause the project to get to or very near the performance peak. In a rugged landscape, however, the project may end on a relatively small local peak, far away from the highest peak.

Building on recommendations the project management and the new product development literature, [59] identify two strategies to complement traditional risk management for cases of unk unks, namely trial-and-error learning and selectionism. A review of project management frameworks in product innovation management by Sperry and Jetter [62] also identifies these two fundamental concepts, alongside 
2015 Proceedings of PICMET '15: Management of the Technology Age

TABLE 3. RECOMMENDED PROJECT MANAGEMENT APPROACHES FOR DIFFERENT LEVELS OF UNCERTAINTY

\begin{tabular}{|c|c|c|c|}
\hline Nature of the project & $\begin{array}{l}\text { Technology } \\
\text { Uncertainty }\end{array}$ & $\begin{array}{l}\text { Market } \\
\text { Uncertainty }\end{array}$ & Recommended project management approach \\
\hline $\begin{array}{l}\text { Innovative New Product, } \\
\text { new functionality with } \\
\text { potential to change current } \\
\text { technology paradigm; } \\
\text { market adoption by } \\
\text { visionaries }\end{array}$ & High & High & $\begin{array}{l}\text { Trial-and-Error: initial planning steps are non-linear, non-orderly, and } \\
\text { non-predictable and simultaneously focused at discovery and feedback } \\
\text { learning } \\
\text { (equivalent to trial-and-error in }[58],[59] \text { ) }\end{array}$ \\
\hline $\begin{array}{l}\text { Significant Improvement } \\
\text { Product } \\
\text { Significantly improved } \\
\text { functionality through } \\
\text { adding and removing of } \\
\text { features that makes the } \\
\text { product attractive to } \\
\text { mainstream adopters and } \\
\text { adjacent markets }\end{array}$ & $\begin{array}{l}\text { Medium to } \\
\text { Medium-High }\end{array}$ & $\begin{array}{l}\text { Medium to } \\
\text { Medium-High }\end{array}$ & $\begin{array}{l}\text { Planning steps are focused at testing/validating assumptions through } \\
\text { experimentation and feedback, but the approaches differ with regard to } \\
\text { their initial structure: } \\
\text { - } \quad \text { Recursive: loosely coupled, unstructured steps are decided on } \\
\text { as feedback information becomes available, making the } \\
\text { actual project activities and outcome relatively unpredictable. } \\
\text { (equivalent to trial-and-error in [58], [59]) } \\
\text { Evolving: project steps and feedback loops are planned } \\
\text { upfront, but length and outcome of each feedback cycle are } \\
\text { unknown. (equivalent to trial-and-error in [58], [59]) } \\
\text { Selectionism: project steps are designed to generate and test } \\
\text { alternative solutions in parallel and select the best alternative } \\
\text { after testing. Learning occurs ex-post. (equivalent to } \\
\text { selectionism in [58], [59]) }\end{array}$ \\
\hline $\begin{array}{l}\text { Incremental New Product } \\
\text { moderate changes in } \\
\text { existing functionality, } \\
\text { targeted at existing } \\
\text { markets }\end{array}$ & $\begin{array}{l}\text { Low to Low- } \\
\text { Medium }\end{array}$ & $\begin{array}{l}\text { Low to Low- } \\
\text { Medium }\end{array}$ & $\begin{array}{l}\text { Linear: Process consists of a fixed sequence of several defined gates and } \\
\text { stages }\end{array}$ \\
\hline
\end{tabular}

recursive and evolving approaches that are discussed, as descriptive frameworks, in the literature (see Table 3, adapted from [62]).

Trial-and-error learning builds on experimentation by introducing an early version of the product to the customer. The experiment can take the form of a product concept test (e.g. based on concept descriptions or prototypes), but also sales of a functional early product version. Tests can also pertain to critical business model elements. In entrepreneurship practice, experiments are increasingly characterized by Minimum Viable Product (MVP) Testing, which aims at gaining market validation before investments are mounted on scaling the business. In this context, MVPs are often mock-ups of software, e-commerce offerings, or landing pages of future companies. Customers demonstrate their willingness to accept the product either by buying the offering despite its limited feature set or by attempting to buy the future product and making some kind of early stage commitment (e.g. pre-ordering or leaving their e-mail to receive further notice when the offering will become available). In the context of extreme programming (XP) experimentation takes the form of building products iteratively through a number of short feedback cycles: a first product release is designed to fulfill customers' very basic needs and as a means to obtain feedback. Complexity is added to each following release to address unfolding customer needs but always guided by the principle to implement the least amount of features that can be expected to fulfill the expressed need. Releases occur in short intervals (2 months) and plans, schedules, and sometimes even contractual agreements pertain to the work required until the next release, rather than everything that needs to be done to complete the project. Experimentation-based approaches are different in what they test, ranging from entire business ideas to specific functional aspects of a software product, but they all are characterized by the use of boundary objects to facilitate high-quality feedback from real-world customers.

Selectionism characterizes a strategy of pursuing multiple candidate solutions until the best solution can be identified [63]-[65]. Similarly to Darwinian selection, success depends on creating solutions with sufficient variability so that at least one of the variations is good enough to solve the problem and to apply evolutionary pressure. The latter takes the form of clear decision points and withdrawal of resources to force the selection of the best available solution and the end of all other trials [66] Pharmaceutical companies, for example, often fund research of different target molecules for addressing the same medical problem in order to have backup if their lead molecule fails [59] The practice of set-based design at Toyota follows the same principle: different functional groups participating in the development process (e.g. mechanical design and manufacturing) pursue several solutions in parallel and communicate them to the other functional groups. The groups then identify which solutions in each set are also in the feasible set of the other groups and pursue them further. As each groups continues to narrow down its solution set while also making sure that the solutions remains within the feasible set for the other groups, the final design evolves [67].

A question of fundamental importance is the specific context under which trial-and-error and selectionism should be used. Sommer and Loch model various scenarios and conclude that trial-and-error learning is superior to selectionism for all but one scenario, in which the 


\section{Proceedings of PICMET '15: Management of the Technology Age}

unforeseeable uncertainty of the project is caused by its many interdependencies, rather than its sheer size, and in which there are credible trials for true market performance [58].

\section{E. Summary of the state-of-the-art}

The literature on product innovation management reviewed above acknowledges a need for targeted flexibility. For the most part, it assumes that this can be achieved within the popular phase-gate-approach, by adapting the length of stages, the nature of the deliverables, and the review criteria to each project's particular needs. Moreover, within each phase, project managers are free to choose how they want to approach the tasks and can, for example, chose trial-and-error or selectionism. In the front-end, practitioners often rely on informal approaches that evolve as the projects unfolds, whereas gated project management frameworks are recommended later in the development cycle. Even though the front-end aims to reduce uncertainty and provide stable plans for the project, radically new innovations encounter high level uncertainties during project execution, which results in a heavier emphasis on prototyping, experimentation, and making up plans as the project moves along than is the case for incremental projects. When it comes to radical new products, product development consequently has a need for ambidexterity through integration that enables teams to cycle between explorative and exploitative project activities. Ambidexterity isn't the result of a single practices but results from a combination of project management culture, competencies, and project management approaches. One of the project management approaches that enables ambidexterity is the flexible adaption of how a project is planned and executed, dependent on the ambiguity and uncertainty of the project. The project management literature, however, does not yet provide an integrated framework for such "targeted flexibility". The following section therefore introduces the first stage of an inductive study that investigates managerial practices that could inform such a framework.

\section{A CASE STUDY OF MANAGERIAL PRACTICE}

In order to inform the future development of a framework for targeted flexibility, the goal of the inductive research presented in this paper is to investigate the nature of ambiguity and uncertainty, as well as the practical approaches used to manage them in the context of new product development projects. Research is still ongoing and the following sections describe initial results of the first two research stages: In phase one, R\&D managers from 7 companies were interviewed and asked to comment on their standard development practices, as well as on specific projects in which the project team followed an approach different from the standard. Results of this phase informed the interviews in phase two, during which 4 R\&D managers within the same company commented on a total of 12 projects that followed standard and non-standard processes.
Pre-interviews and analysis of company websites and annual reports were used to ensure that the companies frequently launch new products with varying degrees of innovativeness. All companies selected for the research are small to mid-size (annual revenue up to 600 million dollars) and organize research and development activities within the same organizational units. The interview respondents had responsibility for multiple product innovation projects as managers or directors of R\&D, product development, and product management. As such, they were familiar with projects that range from incremental improvements and product maintenance to fundamentally new products and platform initiatives.

Interviews were based on a semi-structured interview protocol that consisted of three main parts: In the first part, the respondent was asked to describe the standard process (or standard processes) their organization employs for managing product development projects. This serves as a means to establish a baseline understanding of company practices and put respondents at easy by acknowledging that the company usually follows a rational, structured approach. The second part of the interview uses episodic interviewing and asks respondents to recall a past project that has deviated from this baseline process. The respondent describes the reasons for the deviation, the way in which the project unfolded, the people involved, and the project outcomes. He or she is also asked to characterize the project uncertainty and the project management approach by selecting descriptive statements from a list of options and to show the uncertainty level of the project on a graph. For example, a project is identified to have 'medium to low' technology uncertainty when the respondent agrees with the statement that at the onset of, we had a good understanding of the technology with only few uncertainties. In the third part of the interview, respondents are asked to recall another project that deviated from the baseline process, but differed from the first project in that it had a different outcome or different reasons for not employing the standard process. The interviews such contained information about the standard process and at least two different projects that did not follow this process. All interviews were recorded and two researchers wrote their field notes and interview summaries separately.

\section{A. Preliminary results of phase 1}

The managers in the phase 1 interviews all reported that their companies employ a linear product development process, which was frequently referred to as 'Stage-Gate'. This process is used as a standard to manage projects with different degrees of innovation, ranging from fundamentally new product platforms to incremental product updates. One company uses two different linear process models for marketdriven development projects that respond to market opportunities and technology development projects that originate with an idea by technologists and/or a gap in the technology roadmap. The market-driven projects are carefully analyzed and planned upfront and only receive 
approval if a detailed business case is presented. Technology projects that show future promise for the market are approved with less formality and upfront planning. Their budgets are typically small (under $\$ 100 \mathrm{~K}$ ).

Within the linear process framework, the front-end is treated as a distinctly different phase and either intentionally designed or at least accepted to be iterative. It is intended to enable a linear project management approach by reducing uncertainty and by providing clear project scopes and timelines. All respondents, however, have reported that they deviate from their company's baseline process, typically by moving projects through gates, even though information is still missing or by skipping review gates all together. The main reasons given were time-pressure and/or upper management decisions to move a project ahead because of a closing market window or a competitor's action. Moreover, projects are moved forward despite missing data because the data is not and will not be available. Without the detailed upfront planning assumed in linear process frameworks, teams resort to a learning based approaches for the remainder of the project. The interviews did not provide sufficient data to draw conclusions as to how this practice impacts overall project success. They did, however, confirm that many innovation projects do not start with the detailed upfront plans and contingency plans that linear project management frameworks aim to achieve and assume for later project stages. In fact, they appear to be more of an exception than a rule, particularly in the case of products that are not incremental enough for markets and technologies to be well known.

Tables 4 and 5 summarize the findings

TABLE 3 SHORT OVERVIEW OF STUDY INTERVIEWS, PART1

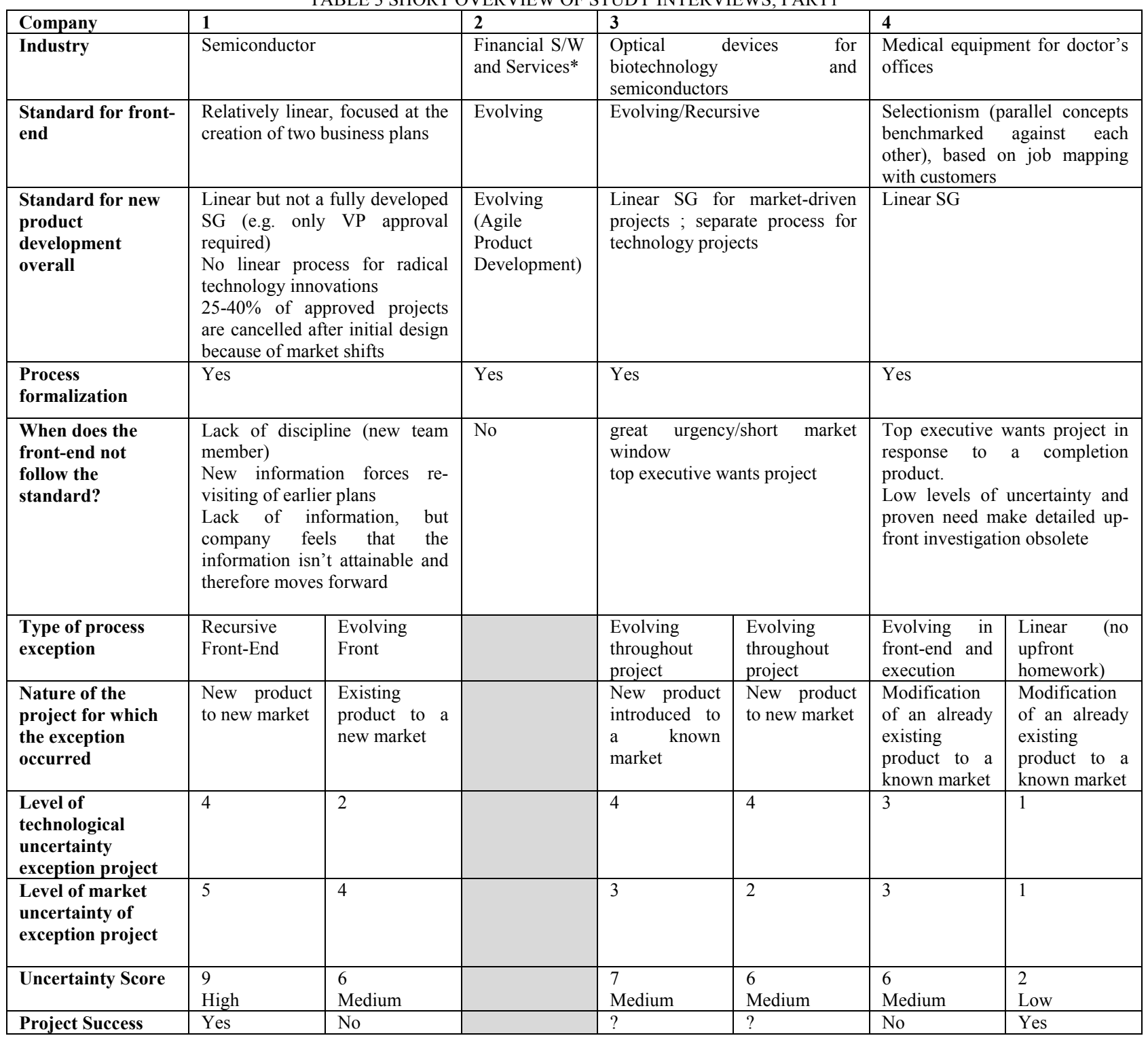


2015 Proceedings of PICMET '15: Management of the Technology Age

TABLE 4 SHORT OVERVIEW OF CASE STUDY INTERVIEW, PART 2

\begin{tabular}{|c|c|c|c|c|c|c|}
\hline Company & \multicolumn{2}{|l|}{5} & \multicolumn{2}{|l|}{6} & \multicolumn{2}{|l|}{7} \\
\hline Industry & \multicolumn{2}{|c|}{$\begin{array}{l}\text { Software development group for } \\
\text { large consumer electronics } \\
\text { company }\end{array}$} & \multicolumn{2}{|c|}{$\begin{array}{l}\text { Measurement equipment for } \\
\text { semiconductor industry }\end{array}$} & \multicolumn{2}{|c|}{ Laser technology } \\
\hline $\begin{array}{l}\text { Standard for } \\
\text { front-end }\end{array}$ & \multicolumn{2}{|c|}{ Evolving (agile development) } & \multicolumn{2}{|l|}{ Recursive } & \multicolumn{2}{|l|}{ Evolving } \\
\hline $\begin{array}{l}\text { Standard for NPD } \\
\text { in general }\end{array}$ & \multicolumn{2}{|l|}{ Evolving (agile) } & \multicolumn{2}{|c|}{$\mathrm{SG}$, but only recently introduced } & \multicolumn{2}{|c|}{ Loose, closer to evolving than to linear } \\
\hline $\begin{array}{l}\text { Process } \\
\text { Formalization }\end{array}$ & \multicolumn{2}{|l|}{ Yes } & \multicolumn{2}{|l|}{ Yes } & \multicolumn{2}{|c|}{$\begin{array}{l}\text { Very little (some standards for documentation } \\
\text { and analysis) }\end{array}$} \\
\hline $\begin{array}{l}\text { When does the } \\
\text { front-end not } \\
\text { follow the } \\
\text { standard process? }\end{array}$ & \multicolumn{2}{|c|}{$\begin{array}{l}\text { Internal customer provided } \\
\text { detailed requirements, enabling a } \\
\text { shorter exploration phase } \\
\text { Third party needs determined SG }\end{array}$} & \multicolumn{2}{|c|}{$\begin{array}{l}\text { Made-to-order custom products } \\
\text { with relatively low market } \\
\text { uncertainty made the fuzzy front- } \\
\text { end relatively linear. } \\
\text { Technology challenges caused } \\
\text { project to follow a evolving } \\
\text { pattern, even after it was in } \\
\text { execution }\end{array}$} & \multicolumn{2}{|c|}{$\begin{array}{l}\text { Difficult to determine as there is not clearly } \\
\text { defined process } \\
\text { Strong internal sponsor (e.g. top management) } \\
\text { changes project dynamics }\end{array}$} \\
\hline $\begin{array}{l}\text { Type of process } \\
\text { exception }\end{array}$ & $\begin{array}{l}\text { Short cut } \\
\text { Evolving in } \\
\text { early stages }\end{array}$ & $\begin{array}{l}\text { Linear (stage } \\
\text { gate) to comply } \\
\text { with third party } \\
\text { throughout } \\
\text { project }\end{array}$ & $\begin{array}{l}\text { Linear } \\
\text { (compression), } \\
\text { particularly in } \\
\text { early stages }\end{array}$ & $\begin{array}{l}\text { Evolving } \\
\text { in late } \\
\text { stages }\end{array}$ & $\begin{array}{l}\text { Front-End } \\
\text { more } \\
\text { linear than } \\
\text { usual }\end{array}$ & $\begin{array}{l}\text { Front end more recursive than } \\
\text { usual }\end{array}$ \\
\hline $\begin{array}{l}\text { Nature of the } \\
\text { project for which } \\
\text { the exception } \\
\text { occurred }\end{array}$ & $\begin{array}{l}\text { Modifi- } \\
\text { cation of an } \\
\text { already } \\
\text { existing } \\
\text { product to a } \\
\text { known } \\
\text { market }\end{array}$ & $\begin{array}{l}\text { New product to } \\
\text { a known market }\end{array}$ & $\begin{array}{l}\text { New product to an } \\
\text { existing market }\end{array}$ & $\begin{array}{l}\text { New product } \\
\text { to existing } \\
\text { market }\end{array}$ & $\begin{array}{l}\text { New } \\
\text { product to } \\
\text { a known } \\
\text { market }\end{array}$ & $\begin{array}{l}\text { Existing product for a known } \\
\text { market }\end{array}$ \\
\hline $\begin{array}{l}\text { Level of } \\
\text { technological } \\
\text { uncertainty of } \\
\text { exception project }\end{array}$ & 5 & 4 & 5 & 4 & 2 & 1 \\
\hline $\begin{array}{l}\text { Level of market } \\
\text { uncertainty of } \\
\text { exception project }\end{array}$ & 5 & 3 & 3 & 3 & 1 & 1 \\
\hline $\begin{array}{l}\text { Uncertainty } \\
\text { Score* }\end{array}$ & $\begin{array}{l}10 \\
\text { High }\end{array}$ & $\begin{array}{l}7 \\
\text { Medium }\end{array}$ & $\begin{array}{l}8 \\
\text { Medium-High }\end{array}$ & $\begin{array}{l}7 \\
\text { Medium }\end{array}$ & $\begin{array}{l}3 \\
\text { Low }\end{array}$ & $\begin{array}{l}2 \\
\text { Low }\end{array}$ \\
\hline
\end{tabular}

\section{B. Preliminary results of phase 2}

Phase two of this research investigated how a standardized, linear project management framework is employed across a company with different product innovation projects. The chosen case study company is a high tech equipment manufacturer that has adopted Stage-Gate as a standard project management approach. The interview protocol from phase 1 was modified and used to interview the managers of four development groups, each of which focuses at a different aspect of the product. Each interviewee was asked to give 3 cases of past projects that they have knowledge of. The resulting 12 case descriptions were analyzed with regard to the project management process used, the type of the project, its origin, and the level of ambiguity/uncertainty associated with this project.

The company executes a broad range of product innovation and technology development projects that are targeted at bringing cutting edge innovation to market, to improve current products in response to market and competitor changes, and to customize products according to customers' needs. The company classifies the projects into the following categories:

Strategic projects: these are radical innovational and research-focused projects, which aim to create the next generation technology. They are fuzzy in nature, have a high level of uncertainty, no clear expectations of the results, and usually are managed by 'trial and error' with poor documentation. Influential product champions often trigger strategic projects, such the company founder who is a recognized technical expert.

Product development projects: these are usually relatively incremental innovations that respond to needs that were identified through market research or to produce the next generation of the product. Projects are well planned, have clear objectives and medium-low level of uncertainty. Stage-gate has been used in practice to manage this type of project. 


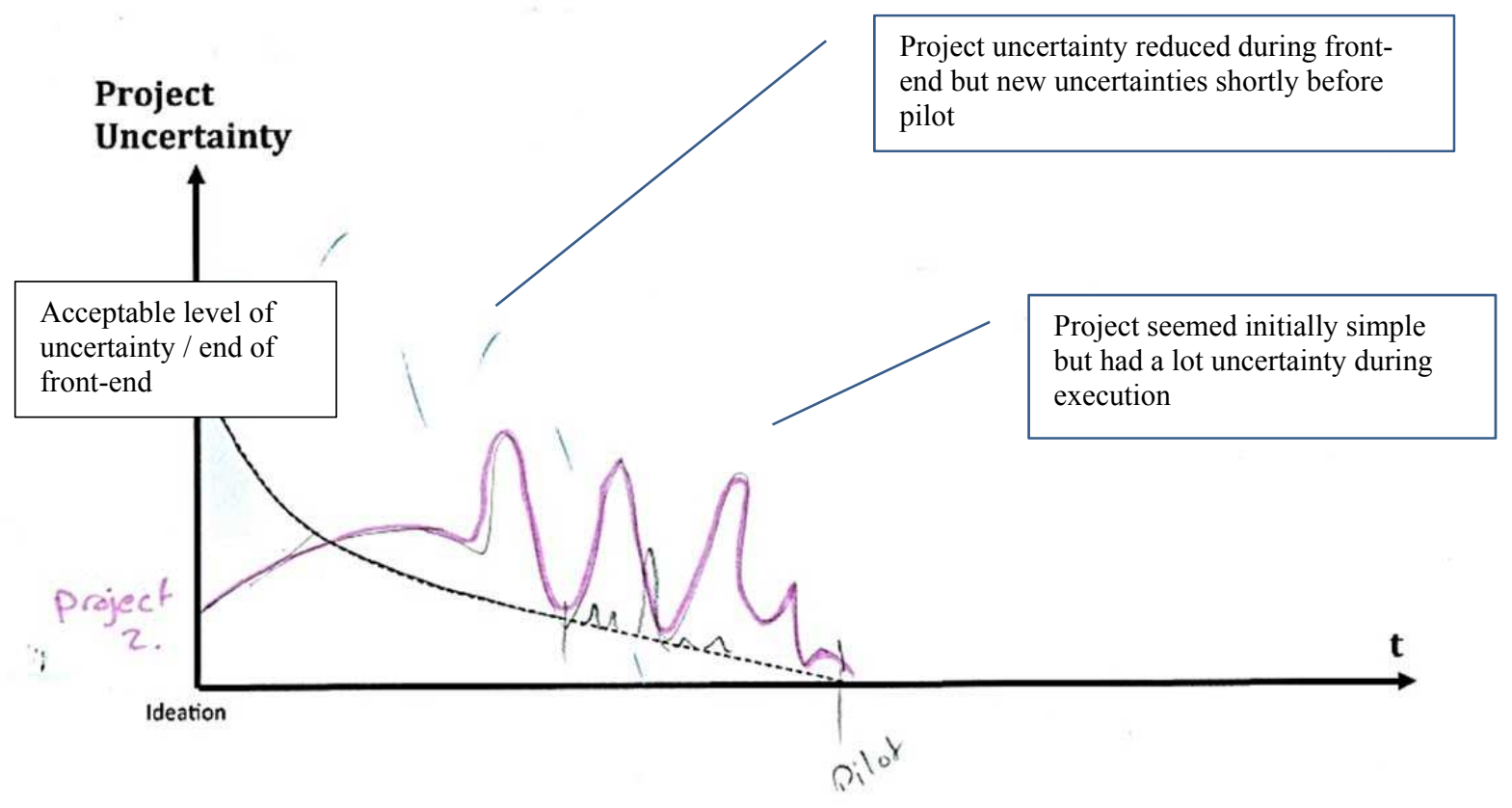

Figure 3: Uncertainty level for two different projects, represented by a respondent

Customized projects: customer driven projects, which require adding features to existing products or merging the capabilities of two different products, based on customer requests. Most of customized projects are about adding or adjust features. However, they can be large and complex and often suffer from feature and schedule creep. They may not be strategically relevant, but because they are targeting exiting customers, they are important and managed with priority. A key challenge for these projects is the bidding process: when customers inquire about a customization, they expect a binding quote in a relatively short period of time, leaving little time for upfront homework. Moreover, the company does not want to overinvest in planning activities for a project that may or may not happen, depending on if the customer decides to order or not. As a result, customized projects have different level of uncertainty. Respondents reported that in some cases uncertainty was perceived to be low at the start of the project, but increased in the later stages when customer requirement became clear or technical challenges became apparent. Figure 3, which was created by a respondent during the interview, illustrates this observation.

Respondents consistently comment that a more rigorous planning process could have avoided some of the challenges and rework, but not all of it.

Sustaining projects: Sustaining projects are a second special case of product development projects. They are planned and executed within a functional team in $R \& D$, typically in order to address a technical or business need, such as cost reduction or standardization across different products. Project budgets are small (typically less than $\$ 10,000)$ and the need for coordination with other functions or upper management is minimal. Sustaining projects are therefore managed outside of the phase-gate process with approaches that are up to the project team. One example given by a respondent was a cost reduction of the bill of materials by $\$ 1,500$. The project was managed as a WIG project (wildly important goal), which means that the project team had a sense of urgency and ideas for improvements were solicited, evaluated, and quickly implemented. Progress was tracked weekly against a task list and simple measures (total cumulative savings, $\%$ of ideas in evaluation, implementation, etc.). The process had no gate reviews. It had very little uncertainty because the objectives were clear and the course of action was technologically clear as well.

The company is relatively new to formalized project management in its $R \& D$ organization. The plan is to apply its phase-gate review process, which is integrated with project management processes, to all projects with a significant development effort, including large sustaining efforts and large custom projects. "Significance" of the development effort is not solely determined by the budget but can also apply to small projects with less than $\$ 10,000$ budgets. Small projects, however, go through simplified gate reviews, where (by one respondents' estimate) as much as $90 \%$ of the review documents and criteria may not apply. When fully implemented, the project management office targets to have $70 \%$ of the R\&D budget managed under the phase-gate process. The actual number of projects managed through this framework however, appears to still be small - one engineering manager estimated that three years into the process change, only about $10 \%$ of all projects (but most major initiatives) follow phase-gate. Moreover, the classification of project to determine how they will be managed is problematic, as illustrated by this quote "We do not have a defined process and we still do not have a clear definition of different projects". It seems a matter of project 
sponsor (sales vs. somebody else) and the origin of the project, rather than the uncertainty profile of the project, that determines how it is managed.

Respondents give different reasons for why the company is changing its approaches to project management in product development. The respondent from the project management office emphasizes transparency, which will allow upper management to more precisely forecast finances (project budgets and expected future project returns), project completion and product release dates, and current and future use of engineering resources. Gate reviews therefore require updated financials, a comparison of project budget and actual, a short report on risk factors (including impacts and contingency and mitigation) and information on staffing actuals and needs. These insights are expected to support a streamlining of the project pipeline so that it only contains projects that are important and will be successful, that are actively worked on, and that are sufficiently staffed. Engineering managers agree that the company has difficulties in prioritizing and culling projects in its development pipeline and understand that upper management wants more visibility. However, they are generally more concerned with how to best manage individual projects and express doubts that one framework fits all needs, particularly as they are often using (planned and unplanned) iterative approaches. They particularly worry that projects that occur within functional groups, such as many of the sustaining projects, will not only not benefit from being more closely managed and monitored but may actually suffer because it complicates things for project teams that currently require very little coordination. They also expressed doubts that the added reporting will result in substantial improvements.

\section{CONCLUSION: EMERGENT THEMES FOR A FUTURE FRAMEWORK OF TARGETED FLEXIBILITY}

Based on a review of the literature and the investigation of project management practices in eight companies, this study provides the foundations for a yet-to-be-developed framework for target flexibility. The key insights, as well as the future research needs that result from them, can be summarized as follows:

First, the challenge of ambidexterity, which results in a need for targeted flexibility [2], is real: the case studies show that product development teams need to balance exploration and exploitation not only within the same product development organization but, in particularly in the case of radical new innovation, even within the same development project. Project management activities can support this ability, among others, by providing documentation of knowledge for future exploitation, by increasing the transparency and plannability of projects, and by helping plan and support explorative strategies [50]. The case study companies therefore frequently aimed to increase project management proficiency. Yet, project management practices may also hinder exploration as the literature highlights [2],
[22] and some of the case study participants express concerns about. Future research needs to explore these relationships, as they unfold in practice, in more detail in order to reach recommendations for targeted flexibility that do not have unwanted effects.

Second, the front-end is distinct from later project stages and follows iterative and plan-as-you-go approaches [25], [26]. Its fundamental aim is to reduce uncertainty enough for planning-and-control driven project management to take over, yet the literature and our case studies show that it often fails to succeed in doing so. One reason may be the inherently high level of uncertainty for radical innovation. Also, resources dedicated to uncertainty reduction in the front-end may not be sufficient, particularly when "sticky" customer knowledge has to be transferred in, as is the case with the customized projects in study 2 . Future inquiries need to better understand the root causes of uncertainty as they are experienced on the ground. This will help answer which of the many assumed reasons - lack of planning, blind spots, novelty and a resulting lack of information, dynamic complexity in large projects, etc. - plays out in which way. Moreover, the project management discipline needs to provide more focus and guidance for the pre-project and early initiation stage, which it currently largely ignores.

Third, as a result of unknown unknowns that emerge in later project execution stages, project management in $R \& D$ is approached with great flexibility and frequently revised plans, timelines, and budgets. This flexibility is enabled by $\mathrm{SG}$, which creates a process for reviewing projects and revising approaches with upper management buy-in [16]. However, our case studies show that flexibility is rarely "designed" into the project plans upfront, for example in the form of clearly planned parallel trials (selectionism) or defined trial-and-error paths. A likely explanation is that stage-gate is too "macro" of a framework to focus on the details of future project execution, whereas project management practices are too focused on risk management for known unknowns. A logical starting point for embedding learning based approaches into project practice are changes to current project planning standards. New standards need to shift the focus from planning and monitoring against plans to planning of learning strategies and monitoring against learning outcomes. Future research will have to investigate how this can occur in practice to inform better project management standards.

Fourth, the case studies show that level of project management sophistication in new product development appears to be low. For example, respondents wrongly equate the State-Gate approach with project management, report on a lack process clarity and frequent exception-making and bypassing of procedures, based on authority, and express even within the same organization - differences of opinion about the goals of project management. It appears that in all companies in our sample, phased-gate approaches from innovation management were earlier deployed than any form of traditional project management and standard project 
management tools are relatively underused. An important question for future research is therefore the transition path towards higher project management maturity: should R\&D organizations follow a traditional path from repeatable processes, over building organizational infrastructure to institutionalized processes and culture? Or should they, if they already apply phased-gate frameworks, chose a different path that better reflects their organizational realities?

The currently ongoing analysis of our data ${ }^{1}$, additional data collection, and future research by the project management and new product development community are likely to shed light on these questions and ultimately contribute to a framework for targeted flexibility

\section{ACKNOWLEDGMENTS}

We wish to thank Project Management Institute for grant funding that has made this research possible. We are also grateful for the valuable insights and comments by John Patton, Paul Newman, Peerasit Patanakul, Richard Sperry, Ron Khormaei, and Terry Cook-Davies.

\section{REFERENCES}

[1] J. G. Rice, M. P., O’Connor, G. C., Peters, L. S., \& Morone, "Managing Discontinuous Innovation," Res. Technol. Manag., vol. 41, no. 3, pp. 52-59, 1998.

[2] S. Lenfle and C. Loch, "Lost Roots: How Project Management Came to Emphasize Control over Flexibility and Novelty," Calif. Manage. Rev., vol. 53, no. 1, pp. 32-55, 2010.

[3] A. J. Shenhar and D. Dvir, Reinventing Project Management. Boston, MA: Harvard Business School Press, 2007.

[4] T. Brady and A. Davies, "Managing Structural and Dynamic Complexity: A Tale of Two Projects," Proj. Manag. J., vol. 45, no. 4, pp. 21-38, 2014.

[5] R. G. Cooper, S. J. Edgett, and E. J. Kleinschmidt, "Portfolio management for new product development: results of an industry practices study," R D Manag., vol. 31, no. 4, pp. 361-380, Oct. 2001.

[6] G. Barczak, A. Griffin, and K. Kahn, "PERSPECTIVE: Trends and Drivers of Success in NPD Practices: Results of the 2003 PDMA Best Practices Study," J. Prod. Innov. Manag., vol. 26, no. 1, pp. 3-23, 2009.

[7] S. Brown and K. Eisenhardt, "Product development: past research, present findings, and future directions," Acad. Manag. Rev., vol. 20, no. 2, pp. 343-378, 1995.

[8] R. G. Cooper, "Perspective : The Stage-Gate Idea-to-Launch Process Update, What's New and NexGen Systems Perspective : and NexGen Systems," J. Prod. Innov. Manag., vol. 25, pp. 213-232, 2008.

[9] S. D. Ulrich, K. T., \& Eppinger, Product Design and Development. Boston, MA: McGraw-Hill/Irwin, 2008.

[10] M. Pina and J. F. S. Gomes, "Order and Disorder in Product Innovation Models 1 Organizational Paradigms :," vol. 12, no. 3, pp. 174-188, 2003.

[11] V. Krishnan and K. T. K. Ulrich, "Product development decisions: A review of the literature," Manage. Sci., vol. 47, no. January 2014, pp. 1-21, Jan. 2001

[12] J. E. Ettlie and J. M. Elsenbach, "Modified Stage-Gate," no. 585, pp. 20-33, 2007.

\footnotetext{
${ }^{1}$ Final results of this study are expected in summer/fall 2015 and will be published at www.pmi.org.
}

[13] R. Sethi and Z. Iqbal, "Stage-gate controls, learning failure, and adverse effect on novel new products," J. Mark., vol. 72, no. January, pp. 118-134, 2008.

[14] V. Krishnan and S. Bhattacharya, "Technology Selection and Commitment in New Product Development: The Role of Uncertainty and Design Flexibility," Manage. Sci., vol. 48, no. 3, pp. 313-327, Mar. 2002.

[15] R. Verganti, "Planned flexibility: linking anticipation and reaction in product development projects," J. Prod. Innov. Manag., vol. 16, no. 4, pp. 363-376, 1999.

[16] R. G. Cooper, Winning at New Products, 4th ed. New York, 2011.

[17] J. a. Daly, A. S. Sætre, and E. Brun, "Killing Mushrooms: the Realpolitik of Terminating Innovation Projects," Int. J. Innov. Manag., vol. 16, no. 05, p. 1250024, Oct. 2012.

[18] R. G. Cooper, "Stage-Gate Systems : A New Tool for Managing New Products," no. June, 1990.

[19] R. W. Veryzer and B. Borja de Mozota, "The Impact of User-Oriented Design on New Product Development: An Examination of Fundamental Relationships*," J. Prod. Innov. Manag., vol. 22, no. 2, pp. 128-143, Mar. 2005.

[20] J. Grönlund, D. Rönnberg Sjödin, and J. Fishammar, "Open Innovation and the Stage-Gate Process," Calif. Manage. Rev., vol. 52, no. 3, pp. 106-132, 2010.

[21] M. Kurkkio, J. Frishammar, and U. Lichtenthaler, "Where process development begins: A multiple case study of front end activities in process firms," Technovation, vol. 31, no. 9, pp. 490-504, Sep. 2011.

[22] J. E. Ettlie and J. M. Elsenbach, "Modified Stage-Gate ${ }^{\circledR}$ Regimes in New Product Development*," J. Prod. Innov. ..., vol. 24, no. 585, pp. 20-33, 2007.

[23] R. Cooper, "Stage-gate systems: a new tool for managing new products," Bus. Horiz., no. June, pp. 44-54, 1990.

[24] R. G. Cooper, "Third-Generation New Product Processes," J. Prod. Innov. Manag., vol. 11, no. 1, pp. 3-14, Jan. 1994.

[25] A. Khurana and S. S. R. Rosenthal, "Integrating the fuzzy front end of new product development," Sloan Manage. Rev., vol. 38, no. Winter, pp. 103-120, 1997.

[26] P. Koen, G. Ajamian, and R. Burkart, "Providing clarity and a common language to the "fuzzy front end," Res. ..., pp. 46-55, 2001.

[27] F. M. Albar and A. Jetter, "An investigation of fast and frugal heuristics for new project screening," Portland International Conference on Management of Engineering \& Technology (PICMET). Portland, Oregon, USA, pp. 824-835, 2011.

[28] D. G. Reinertsen, "Taking the fuzziness out of the fuzzy front end," Res. Manag., vol. 42, no. November-December, pp. 25-31, 1999.

[29] Q. Zhang and W. J. Doll, "The fuzzy front end and success of new product development: a causal model," Eur. J. Innov. Manag., vol. 4, no. 2, pp. 95-112, 2001.

[30] A. Khurana and S. R. Rosenthal, "Towards Holistic 'Front Ends' In New Product Development," J. Prod. Innov. Manag., vol. 15, no. 1, pp. 57-74, Jan. 1998.

[31] M. Rice, D. Kelley, L. Peters, and G. Colarelli O'Connor, "Radical innovation: triggering initiation of opportunity recognition and evaluation," R D Manag., vol. 31, no. 4, pp. 409-420, Oct. 2001.

[32] H. Florén and Frishammar, "From Preliminary Ideas to Corroborated Product Definitions: Managing the Front End of New Product Development," Calif. Manage. Rev., vol. 54, no. 4, pp. 20-43, Jul. 2012.

[33] R. W. R. Veryzer, "Discontinuous innovation and the new product development process," J. Prod. Innov. Manag., vol. 15, no. 4, pp. 304321, Jul. 1998.

[34] B. Verworn, C. Herstatt, and A. Nagahira, "The fuzzy front end of Japanese new product development projects : impact on success and differences between incremental and radical projects," $R \& D$ Manag., vol. 38, no. 1988, pp. 1-19, 2008.

[35] M. W. Lewis, M. A. Welsh, G. E. Dehler, and S. G. Green, "Product development tensions: Exploring contrasting styles of project management," Acad. Manag. ..., vol. 45, no. 3, pp. 546-564, 2002.

[36] C. Govindarajan, V. \& Trimble, "Stop the innovation wars.," Harv. Bus. Rev., vol. 6, no. 1, pp. pp.77-83, 2010. 
[37] M. O'Reilly, C. \& Tushman, "Ambidexterity as a dynamic capability: Resolving the innovator's dilemma," Res. Organ. Behav., no. 28, pp. pp.185-206, 2008.

[38] J. G. March, "Exploration and exploitation in organizational learning," Organ. Sci. 2(1), pp.71-87, vol. 2, no. 1, pp. 71-87, 1991.

[39] P.-K. He, Z.-L. \& Wong, "Exploration vs. Exploitation: An Empirical Test of the Ambidexterity Hypothesis," Organ. Sci., vol. 15, no. 4, pp. 481-494, 2004.

[40] C. A. Tushman, M.L. \& O'Reilly III, "Managing evolutionary and revolutionary change," Calif. Manage. Rev., vol. 38, no. 4, pp. 8-28, 1996.

[41] Lubatkin, M.H. et al., "Ambidexterity and performance in small-to medium-sized firms: The pivotal role of top management team behavioral integration," J. Manag. Educ., vol. 32, no. 5, pp. 646-672, 2006.

[42] A. K. Gupta, K. G. Smith, and C. E. Shalley, "The Interplay Between Exploration and Exploitation.," Acad. Manag. J., vol. 49, no. 4, pp. 693-706, Aug. 2006.

[43] M. Christensen, C.M. \& Overdorf, "Meeting the challenge of disruptive change.," Harv. Bus. Rev., vol. 78, no. 2, pp. 66-77, 2000.

[44] P. McLaughlin, J. Bessant, and P. Smart, "Developing an organisation culture to facilitate radical innovation," Int. J. ..., vol. 44, pp. 298-323, 2008.

[45] S. Raisch, J. Birkinshaw, G. Probst, and M. Tushman, "Organizational Ambidexterity: Balancing Exploitation and Exploration for Sustained Performance," Organ. Sci., vol. 20, no. 4, pp. 685-695, 2009.

[46] J. Birkinshaw, G. Cristina, C. Gibson, and I. Organization, "Building ambidexterity into an organization," MIT Sloan Manag. Rev., vol. 45, no. 4, pp. 47-55, 2004.

[47] Uotila, J. et al., "Exploration, exploitation, and financial performance: analysis of S\&P 500 corporations," Strateg. Manag. J., vol. 30, no. 2, pp. 221-231, 2009.

[48] J. J. P. Jansen, F. A. J. Van Den Bosch, and H. W. Volberda, "Exploratory Innovation, Exploitative Innovation, and Performance: Effects of Organizational Antecedents and Environmental Moderators," Manage. Sci., vol. 52, no. 11, pp. 1661-1674, 2006.

[49] L. Liu and D. Leitner, "Simultaneous Pursuit of Innovation and Efficiency in Complex Engineering Projects-A Study of the Antecedents and Impacts of Ambidexterity in Project Teams," Proj. Manag. J., vol. 43, no. 6, pp. 97-110, Dec. 2012.

[50] Project Management Institute, A Guide to the Project Management Body of Knowledge - PMBOK Guide. Project Management Institute, 2013.

[51] C. Schultz, S. Salomo, U. de Brentani, and E. J. Kleinschmidt, "How Formal Control Influences Decision-Making Clarity and Innovation Performance," J. Prod. Innov. Manag., vol. 30, no. 3, pp. 430-447, May 2013.
[52] R. Cooper, "Perspective: The Stage-Gate ${ }^{\circledR}$ Idea-to-Launch ProcessUpdate, What's New, and NexGen Systems*," J. Prod. Innov. Manag., vol. 25 , no. 3, pp. 213-232, 2008

[53] D. Pons, "Project Management for New Product Development," Proj. Manag. J., vol. 39, no. 2, pp. 82-97, 2008.

[54] H.-H. Schröder and A. J. M. Jetter, "Integrating market and technological knowledge in the fuzzy front end : an FCM-based action support system," Int. J. Technol. Manag., vol. 26, no. 5, pp. 517-539, 2003.

[55] H. Courtney, J. Kirkland, and P. Viguerie, "Strategy Under Uncertainty," Harvard Bus. Rev., vol. 75, no. 6, pp. 67-79, 1997.

[56] S. Schrader, W. M. Riggs, and R. P. Smith, "Choice over uncertainty and ambiguity in technical problem solving," Journal of Engineering and Technology Management, vol. 10, no. 1-2. pp. 73-99, 1993.

[57] F. J. F. J. Milliken, "Three types of perceived uncertainty about the environment: State, effect, and response uncertainty," Acad. Manag. Rev., vol. 12, no. 1, pp. 133-143, 1987.

[58] S. Sommer and C. Loch, "Selectionism and learning in projects with complexity and unforeseeable uncertainty," Manage. Sci., vol. 50, no. 10, pp. 1334-1347, 2004.

[59] S. C. Sommer, C. H. Loch, and M. T. Pich, "Project Risk Management in NPD," in Handbook of New Product Development Management, C. H. Loch and S. Kavadias, Eds. Amsterdam, 2008, pp. 439-465.

[60] M. T. Pich, C. H. Loch, and A. De Meyer, "On Uncertainty, Ambiguity, and Complexity in Project Management," Manage. Sci., vol. 48, no. 8, pp. 1008-1023, Aug. 2002.

[61] R. J. Lempert, S. W. Popper, and S. C. Bankes, Shaping the Next One Hundred Years: New Methods for Quantitative, Long-Term Policy Analysis. .

[62] R. Sperry and A. Jetter, "Theoretical framework for managing the front end of innovation under uncertainty," in PICMET '09 - 2009 Portland International Conference on Management of Engineering \& Technology, 2009, pp. 2021-2028.

[63] E. Dahan and H. Mendelson, "An extreme-value model of concept testing," Manage. Sci., vol. 47, no. 1, pp. 102-116, 2001.

[64] C. H. Loch, C. Terwiesch, and S. Thomke, "Parallel and Sequential Testing of Design Alternatives," Manage. Sci., vol. 47, no. 5, pp. $663-$ 678, 2001.

[65] R. G. McGrath, "Exploratory learning, innovative capacity, and managerial oversight," Academy of Management Journal, vol. 44, no. 1. pp. 118-131, 2001.

[66] C. H. Loch, A. De Meyer, and M. T. Pich, Managing the Unknown: A New Approach to. John Wiley \& Sons, Inc., 2007.

[67] D. K. Sobek, I. I. Allen, and C. W. Jeffrey, "Toyota s Principles of SetBased Concurrent Engineering," 1999. 